\title{
Are the Competency-Based Risk Management Certificate Holders Ready for Change? A Descriptive Study of Readiness for Change
}

\author{
Chintya Shafira M.1, Ita N. Manurung2, Raisa F. Aini' ${ }^{3}$, Wytla N. R. Atmaja4 \\ ${ }^{1}$ CyberWhale, Indonesia \\ ${ }^{2}$ Aether, Indonesia \\ 3, 4 LSP MKS, Indonesia
}

\begin{abstract}
Organizations need to make effective changes to address VUCA conditions to survive and be sustainable. The readiness of members of the organization to make changes plays an essential role in ensuring the effectiveness of organizational's change. As a member of an organization, the risk management certificate holder is expected to be capable of ability and psychologically ready for organizational changes in implementing risk management. This study aims to provide empirical evidence regarding the readiness of competency-based risk management certificate holders to make changes, especially to implement more mature risk management in organizations. This study used a quantitative descriptive approach with a survey method. The survey was conducted online using a self-administered questionnaire modified and adapted from the Organizational Readiness for Implementing Change measurement tool. The sample in this study focused on individuals who have a general competency-based risk management certificate-the sampling technique conducted by convenience sampling technique. Regarding data analysis, the researcher used descriptive statistical analysis. This study indicates that $54.5 \%$ of competency-based risk management certificate holders have a high level of readiness compared to individuals in their group. It shows that risk management certificate holders have high readiness to make changes to implement risk management in their organization. The findings of the two dimensions also form the variable, namely, change commitment and change efficacy. The results show that the competency-based risk management certificate holders' change commitment impacts their readiness to make changes than their change efficacy. It indicates that the certificate holders have a higher share resolved to pursue the action than their shared belief in the collective capabilities to organize and execute the change in the organizations. From the findings of this study, organizations can develop strategies to further increase the confidence of their shared capabilities in organizations, especially for individual risk management certificate holders, so that the effectiveness of changes made by the organization in implementing risk management will be higher.
\end{abstract}

Keywords: readiness for change, risk management certification holder, change commitment, change efficacy, risk management

\section{INTRODUCTION}

This is an open access article under the CC-BY-NC license.

An increasingly complex global economy has had a significant impact in various industrial sectors and raised awareness of the importance of proactively managing risk. Risk management is considered essential to continue protecting the value and creating other added values. On the other hand, the work environment has transformed into a more modern and integrated direction towards a new reform era (Sarkar, 2016). This condition gives rise to a phenomenon known as VUCA (Volatility, Uncertainty, Complexity, and Ambiguity) (Lee Kaivo \& Lauraeus, 2017). Volatility is a dynamic of quick change in various things, for example, technology, economy, politics, society, and lifestyle. 'Uncertainty' refers to the difficulty of predicting an issue or event that will occur, including the impact it will have. 'Complexity' means the level of difficulty the organization faces which can cause disruption or chaos. Meanwhile, 'Ambiguity' is the fact that mixes from various conditions, which causes the intent of the fact to seem floating and full of obscurity (Alijoyo, 2020).

Each of the characteristics of VUCA can be the source of risk that encourage organizations to manage these sources of risk well, so the risk will not have destructive impacts (Interview 1,2021) on the organization in the future. A systematic, measurable, and controlled approach must be prioritized in handling these risks so that later it is hoped that the sources of emerging risks can turn into new opportunities for the organization (Interview 2, 2021). In this condition, risk management carries out its role and function to set a specific limit in realizing opportunities and achieving related targets. Risk management has a role in identifying and evaluating each risk related to specific conditions the organization faces (Kalinga \& Patrick, 
2018). Therefore, an organization needs to implement a mature risk management system to respond to the challenges of VUCA in order to continue to protect the existing organizational value and create other added value for the organization to grow and be sustainable.

Organizations establishing and implementing a mature risk management system are closely related to human resources (HR). Human resources become "actors" who play an essential role in running the organization's existing system. The quality and competence of human resources are fundamental for the organization because they can determine the organization's direction in responding to changes. In addition, human resources also play an essential role as an initiator that will bring up various initiatives and strategies in running the existing system. In this case, one of the critical aspects that human resources should have is a readiness to make changes in the organization. In this context, one of the changes that organizations can make in responding to the challenges of VUCA is to implement risk management carefully. So, the readiness expected to be formed in the organization members is the readiness for changes to implement an increasingly mature risk management system to achieve better organizational conditions in the future.

Weiner (2009) states that organizational readiness for changes refers to organizational members' psychological and behavioral conditions to take actions involved in implementing changes in the organization. The organization's readiness for changes is also reflected in each individual's collective readiness in an organization, including how each sees the changes. This readiness is built from conditions of readiness (change commitment) and ability (change efficacy). A high level of readiness indicates organizational members are more likely to initiate a new change or initiate existing changes, exert more significant effort(s) to implement a change, and display more cooperative behavior to implement proposed changes more effectively (Shea et al., 2014). Weiner (2009) also explains that readiness for changes is situational, depending on the content and context of the change itself. The organization's changes content and context must carefully implement a risk management system in this study. The content and context of the organization's changes are to implement a mature risk management system. Thus, in this case, organizational readiness can also be related to the existence of an informational assessment (measurement of information) of a specific understanding context. It can be one of the benchmarks that will indicate the extent of work competence and individual readiness to make the change itself.

In ISO 17024:2012, competence is the ability to apply knowledge and skills to achieve specific results. Furthermore, in Law Number 13 of 2003, it is stated that work competence is the workability of each related to aspects of knowledge, skills, and work attitudes according to the standards set. It means that every individual who works must have appropriate and adequate knowledge, skills, and work attitudes in carrying out his/her work. On the other hand, referring to the Guidelines for the National Professional Certification Agency (BNSP) No. 301, Rev. 1 of 2013, there is an explanation that one form of official and written legitimacy of work competence is a competency certificate. Therefore, the statement can be interpreted that the competence certificate acknowledges the individual's competence and compliance with applicable regulations. Likewise, in the context of risk management, risk management competency certificates are expected to be the capital for individuals to gain recognition for their competencies and knowledge.

In this case, individuals with risk management certification are expected to help organizations better prepare to implement a more mature risk management system to deal with VUCA. They are officially recognized as having competence and knowledge related to risk management. Thus, the assumption is that organizations with members with risk management certificates can have high readiness to implement a mature risk management system to achieve organizational goals and sustainability. However, this assumption needs to be empirically proven true. Therefore, this study seeks to empirically describe organizational readiness, reflected in the readiness of competency-based risk management certificate holders in Indonesia to make changes to implement a more mature risk management system in the organization.

\section{LITERATURE REVIEW}

\section{Risk management}

Within the organization, risk management is one of the pillars of the GRC that emphasizes an approach to creating and protecting organizational value. Risk management includes principles, frameworks, and processes, in which these three aspects become one unit in their implementation in the organization. 
Permatasari (2020) explained that implementing effective risk management would help organizations identify early problems and provide follow-up to improve. This ability is indeed fundamental in realizing and understanding the changes that the organization will face. In addition, Jia and Bradbury (2020) researched by analyzing the relationship between the application of risk management and company performance. The findings explained that human resource factors play an essential role in improving the organization's performance.

As a fundamental approach, risk management becomes an inherent competence of individuals, where indications of individuals who understand and have risk management competence can be measured through two things, namely risk attitude and risk behavior. In this case, one way to carry out these measurements is through competency and understanding tests carried out in the stages of the risk management certification process. In other words, risk management competency certification is an alternative to measure an individual's understanding of risk management in an organization, especially at the level of risk management implementer.

\section{Risk Management Competency Certificate}

The result of this certification program is in the form of a risk management competency certificate, which is proof of written acknowledgment of mastery in concepts and individual abilities in terms of risk management. In the Indonesian context, the National Professional Certification Agency (BNSP) officially issued the certificate regarding the recommendations given by the Professional Certification Body (LSP)(Pedoman BNSP, 2014).

Indirectly, those who have a risk management competency certificate have fulfilled their obligations to meet the current regulatory needs. Thus, their opportunities to enter the profession and work in risk management tend to be more considered than "common people" who do not have proof of a certificate of competence.

\section{Organizational Readiness for Change}

Organizational readiness for changes is reflected by the readiness of its organizational members, which can be analyzed individually, in teams, departments, or as an organization. According to Weiner (2009), organizational readiness for changes refers to organizational members' change commitment and efficacy to implement organizational change. Readiness in question is a state in which both psychological and behavioral are ready to change. The first aspect of readiness, namely change commitment, refers to the joint determination of organizational members to take actions involved in implementing change. Herscovith and Meyer (2002) provide a more detailed explanation regarding organizational commitment. They observe that organizational members can commit to implementing organizational change because they want to appreciate it, have little choice, or feel obligated. Commitment based on the 'want' motive reflects the highest level of commitment to implementing organizational change. The second aspect of readiness, namely changes efficacy, refers to the shared belief of organizational members in their collective ability to organize and implement the actions involved in implementing change.

According to Bandura (1986), the assessment of organizational members related to efficacy refers to the capabilities of organizational members in performing a behavior. Change efficacy of organizational members will be higher if organizational members have collective confidence with other members in implementing complex organizational changes. Two organizational readiness, change commitment, and change efficacy, are interrelated concepts and are expected to be empirically related. Bandura (2002) states that a low level of confidence in a person's ability to act can interfere with a person's motivation or commitment to engage in the action. Therefore, high readiness must involve feeling like implementing change and believing that members of the organization can do it. They are interrelated concepts and are expected to be empirically related.

Discuss each aspect of readiness to make changes. First, change commitment, commitment readiness is influenced by the change valence. Change valence is an assessment of organizational members regarding the benefits of existing changes. Organizational members can judge the benefits of organizational change for several reasons, but the critical point is how much they value the change. The second aspect is change efficacy, the readiness with confidence that members of the organization can make changes. It is influenced by various factors such as knowledge about the extent to which task demands are related to existing changes (task demands), perceptions of the availability of resources in the organization (resource perceptions), and situational factors such as time in implementation of changes other conditions. In 
addition to the factors above, the readiness for changes can also be influenced by the existing organizational culture, policies, and procedures for changes set by the organization, previous experience in implementing a change in the organization, organizational structure, and organizational structure resources.

\section{Individual factors that affect readiness for changes}

Readiness to change consists of structural and psychological factors. According to Holt et al. (2010), structural/cognitive factors of individual readiness to change consist of knowledge, skills, and ability alignment, namely the extent to which knowledge, competence, and individual abilities follow knowledge, competencies, and capabilities required for change. While the affective factors of individual readiness to change consist of the individual's belief that the changes are made to follow the demands of the situation in the future. In addition, according to Devos (2008), demographic factors such as education and position can affect the readiness for change. Employees with a high educational background have a higher individual readiness for change than those with low education.

\section{RESEARCH METHODOLOGY}

The research approach used is a non-experimental quantitative approach. Meaning that this study used data collected and presented in numbers to answer research questions (Goodwin, 2010), and the variables studied are not manipulated by researchers. In addition, this design was a descriptive study that aims to provide an accurate picture of a particular situation or phenomenon (Christensen, Johnson, \& Turner, 2015). Regarding the research method, the method used was survey research, which is a research method that requires individuals to fill out questionnaires about their attitudes, activities, opinions, and beliefs (Christensen, Johnson, \& Turner, 2015).

The survey was conducted on a sample of respondents holding competency-based certificates in risk management in Indonesia. Researchers conducted convenience sampling, a non-probability sampling technique used in research by asking individuals in the population who are willing and voluntarily to become participants in a study (Christensen, Johnson, \& Turner, 2015).

This study used a self-administered questionnaire, where respondents were asked to fill out the questionnaire by providing answers independently according to their circumstances. This questionnaire was adapted and modified from the Organizational Readiness for Implementing Change measurement tool (Shea et al., 2014). Researchers prepared some questions to measure the variables of Organizational Readiness to Implement for Changes. Two components that form this variable; change commitment and change efficacy. Ten-question items measure the variables in the questionnaire, five questions related to change commitment and five questions related to change efficacy.

Before the data collection, the existing questionnaires were tested on the sample to be studied. The trial was conducted on 30 initial respondents to ensure the reliability and validity of the data from the measuring instrument used. In this study, reliability tests views internal consistency, which refers to the intercorrelations between items in the same test. The measurement of the internal consistency of this questionnaire uses the Cronbach coefficient alpha method. The researcher used IBM SPSS Statistics version 23 software to get the alpha coefficient score. Then, the alpha score will be compared with the criteria of Kaplan \& Saccuzzo (2013). If the score was 0.70 means that the measuring instrument is reliable, whereas if $<0.70$ means that the measuring instrument is not reliable. The results of the reliability test are as follows:

Table 1. Reliability Test

\begin{tabular}{lcl}
\hline & Alpha's Coefficient & Category \\
\hline Readiness to Change & 0.89 & Reliable \\
\hline Change Efficacy & 0.92 & Reliable \\
\hline Change Commitment & 0.92 & Reliable \\
\hline
\end{tabular}

On the other hand, the researcher used the product-moment Pearson correlation validity test for validity test, which uses the principle of correlating each item's score with the total score obtained from the respondent's answers to the questionnaire. The researcher used IBM SPSS Statistics software version 23 to calculate the Pearson correlation score [r]. If the value of $r>$ table's r-value, the question item is 
RSF Conference Series: Business, Management and Social Sciences Vol. 1 (5), 66-73

Are the Competency-Based Risk Management Certificate Holders Ready for Change? A Descriptive Study of Readiness for Change

Chintya Shafira M., Ita N. Manurung, Raisa F. Aini, Wytla N. R. Atmaja

declared valid, while the value of $\mathrm{r}<$ table's r-value, the question item is declared invalid. The results of the validity test are as follows:

Table 2. Validity Test

\begin{tabular}{cccc}
\hline $\begin{array}{c}\text { The items of } \\
\text { questionnaire }\end{array}$ & $\mathbf{r}$ & $\begin{array}{c}\text { Table's r value } \\
(\mathbf{0 . 0 1} ; \mathbf{~ 2 - t a i l e d ;} \mathbf{N}=\mathbf{3 0})\end{array}$ & Validity \\
\hline Item 1 & 0.773 & 0.4629 & Valid \\
\hline Item 2 & 0.767 & 0.4629 & Valid \\
\hline Item 3 & 0.798 & 0.4629 & Valid \\
\hline Item 4 & 0.897 & 0.4629 & Valid \\
\hline Item 5 & 0.878 & 0.4629 & Valid \\
\hline Item 6 & 0.849 & 0.4629 & Valid \\
\hline Item 7 & 0.820 & 0.4629 & Valid \\
\hline Item 8 & 0.810 & 0.4629 & Valid \\
\hline Item 9 & 0.829 & 0.4629 & Valid \\
\hline Item 10 & 0.853 & 0.4629 & Valid \\
\hline
\end{tabular}

Furthermore, the researchers collected online data using a monkey survey for one month, May - June 2021. The researcher obtained 132 risk management certificate holders from data collection who were willing to fill out a questionnaire. Then, the researcher proceeded to the data processing process. The answers given by the respondents will be calculated and processed, then the total score of responses from the questionnaire will be grouped into two categories. This category is made based on group norms, which is seen from the middle value between the range of the lowest and highest data values from group data. By categorizing group norms, the data is compared to fellow groups, namely fellows to risk management competency certificate holders. The following is the distribution of data categorization:

Table 3. Categorization of Data

\begin{tabular}{cccc}
\hline Category & $\begin{array}{c}\text { Readiness For } \\
\text { Implementing Change }\end{array}$ & $\begin{array}{c}\text { Change } \\
\text { Efficacy }\end{array}$ & $\begin{array}{c}\text { Change } \\
\text { Commitment }\end{array}$ \\
\hline High & $\mathrm{X} \geq 41$ & $\mathrm{X} \geq 20$ & $\mathrm{X} \geq 20$ \\
\hline Low & $\mathrm{X}<41$ & $\mathrm{X}<20$ & $\mathrm{X}<20$ \\
\hline
\end{tabular}

The researcher analyzed the data using descriptive statistical analysis to get an idea of the readiness of the risk management certificate holder for changes and an overview of its constituent dimensions, namely change commitment and change efficacy. Before carrying out descriptive statistical analysis, it is necessary to test for normality to determine further statistical tests in obtaining research results. The normality test was carried out using the Kolmogorov Smirnov test, and the results showed that the data was not standard, so the statistical test to be carried out to obtain the results of this study was a nonparametric statistical test.

\section{FINDING AND DISCUSSION}

Organizational change for implementing risk management in a more mature direction is one of the essential things that organizations must prioritize in responding to the VUCA challenge phenomenon. Along with this, organizational change for implementing risk management needs to be carried out effectively, so the change can achieve organizations' objectives to continue to protect and create added value. Effective organizational change is influenced by factors of organizational readiness for changes (Weiner, 2009). The organization's readiness for changes is reflected by the readiness of the organization's members. In this study, the researcher focuses on organizational readiness, which is seen and reflected in the readiness of risk management certificate holders as organization members to make changes, which means to implement risk management more maturely.

From this research, researchers find that the scattered data is homogeneous. In addition, the data obtained by the researcher is also not normal because the significance value is $<0.005$. Here, the evidence gets by the results of the normality test, as follows: 
RSF Conference Series: Business, Management and Social Sciences Vol. 1 (5), 66-73

Are the Competency-Based Risk Management Certificate Holders Ready for Change? A Descriptive Study of Readiness for Change

Chintya Shafira M., Ita N. Manurung, Raisa F. Aini, Wytla N. R. Atmaja

Table 4. One Sample Kolmogorov Smirnov Test

\begin{tabular}{cccc}
\hline & $\begin{array}{c}\text { Readiness for } \\
\text { Implementing Change }\end{array}$ & $\begin{array}{c}\text { Change } \\
\text { Efficacy }\end{array}$ & $\begin{array}{c}\text { Change } \\
\text { Commitment }\end{array}$ \\
\hline $\mathbf{N}$ & 132 & 132 & 132 \\
\hline Sig. (2-tailed) & 0.00 & 0.00 & 0.00
\end{tabular}

From table 4, we can see that the data is not normal means that the respondents have the same perception of the readiness variable in facing this change. This same perception can be formed because respondents have one common thread: the similarity in having a risk management certificate, regardless of differences in position, generation, type of organization, and industry sector. Next, the researcher divides the readiness variable into the high readiness and low readiness categories. The category is also carried out on the dimensions that form the readiness variable, namely, change commitment and change efficacy. From the categorization, the results are as follows:

Table 5. Overview of Readiness to Make Changes

\begin{tabular}{lcc}
\hline \multirow{2}{*}{$\begin{array}{l}\text { Readiness for Implementing } \\
\text { Change }\end{array}$} & Category & Valid Percent (\%) \\
\cline { 2 - 3 } & & \\
\hline Change Efficacy & High & 54.5 \\
\cline { 2 - 3 } & & 45.5 \\
\hline Low & \\
\hline Change Commitment & High & 50.8 \\
\cline { 2 - 3 } & Low & 49.2 \\
\cline { 2 - 3 } & High & 85.6 \\
\hline
\end{tabular}

The data in table 5 show that $54.5 \%$ of the respondents, competency-based risk management certificate holders, have a high readiness to make organizational changes related to the implementation of better risk management, while $45.5 \%$ have a lower readiness. It should be noted that this percentage value appears when respondents are compared to their group, not in general. With this percentage, we can conclude that readiness for changes tends to be higher. In this case, when readiness is high, individuals as members of the organization will take the initiative to change, exert more significant effort and persistence, and behave cooperatively towards the changes set (Weiner, 2009). In addition, with high readiness, organizational members, namely risk management certificate holders, will certainly show a more pro-social tendency to carry out change-related behavior and tend to be more supportive of change efforts beyond their job requirements and role expectations. These things cause the result of high change readiness can affect the implementation of more effective risk management.

Next, the discussion about the results related to the forming dimensions or supporting factors in developing organizational readiness for changes. From Table 5, the result shows that $50.8 \%$ of respondents, competency-based risk management certificate holders, have high change efficacy. This value is not much different from the low change efficacy in risk management certificate holders. As for the aspect of change commitment, the result shows that $85.6 \%$ of respondents assessed that the readiness was high. The results show that the proportion is quite significant. The data interpret that the risk management certificate holders perceive that a committed manner has more impact on them to build readiness for changes than change efficacy. Efficacy is the belief of organizational members in assessing their collective ability to carry out the actions involved in implementing change.

The high level of change commitment in risk management certificate holders can be influenced by the value possessed by risk management certificate holders for changes set by the organization. Weiner explained that high value here could occur because organizational members feel that the organization urgently needs change. Change can solve organizational problems, benefit the organization, and even personally resonate with their core values and others. Regardless of the value possessed by the risk management certificate holder, with a high commitment, the risk management certificate holder provides a positive and high value for organizational change to implement risk management carefully. 
Results in Table 5 also show no significant difference between high and low change efficacy in risk management certificate holders. The results can be affected by more factors that influence the to believe in making changes or change efficacy rather than change commitment. Change efficacy is a comprehensive summary or assessment of the perceived ability to perform a task (Weiner, 2009). Generally, before carrying out tasks related to change, organizational members will obtain, share, assimilate, and integrate information related to: (1) Do we know what it takes to make the change? This question will be related to task demands; (2) Do we have the resources needed? This question will relate to resource perceptions; and (3) Can we implement the changes in the conditions at hand? This question relates to situational factors. If the change efficacy is high, actually this condition illustrates that members of the organization feel confident by not only involving an assessment of themselves, being confident in making changes, but also by involving an assessment that the organization has the human, financial, material, and information resources needed to implement the change correctly. It can be explained from the results of the existing research data that members of the risk management certificate holder in value do have a high level of confidence in readiness for the changes, but it is not significantly different from the group with low confidence. It can be assumed that there are constraining factors that can occur in different organizations so that it affects the confidence of the certificate holder to see his organization in making changes with the three considerations described previously. According to Bandura's theory, it should also be noted that the assessment of change efficacy can also occur over-estimation or under-estimation in the overall assessment so that more accurate information is needed as to why beliefs are formed based on the direct experience of members of the organization.

Apart from categorizing the data, the researcher also conducted a different test with the Kruskal Wallis Test for each existing demographic data. The results of his research are as follows:

Table 6. Different Test of Demographic Factors

\begin{tabular}{cccccc}
\hline & $\begin{array}{c}\text { Type of } \\
\text { Industry }\end{array}$ & Position & Generation & $\begin{array}{c}\text { Type of } \\
\text { Organization }\end{array}$ & $\begin{array}{c}\text { The number } \\
\text { of Certificates }\end{array}$ \\
\hline Kruskal-Wallis H & 14.571 & 6.630 & 2.565 & 0.17 & 0.919 \\
\hline df & 12 & 4 & 3 & 3 & 4 \\
\hline Asymp. Sig. & 0.266 & 0.157 & 0.464 & 0.999 & 0.922 \\
\hline
\end{tabular}

From the results of the tests above, it was found that the asymp value sig. $>0.05$, so it can be concluded that there is no difference between the sample and the difference in demographic data: type of industry, position, generation, type of organization, and the number of certificates. Thus, the data conclude that demographic factors do not influence individual readiness to make changes. Looking at the research of Devos (2008) states that demographic factors such as education and position can affect readiness for changes. This data shows that the job position of the existing sample does not affect the level of readiness formed. As for the education background, the data can be interpreted that all samples are assumed to have the same, having proof of the legitimacy of the competency-based risk management certificate. So, it's the same as the one with a higher educational background. It also can be said that the education to get more familiar with risk management knowledge is the one who formed a high readiness of risk management certificate holders to make changes, especially changes in implementing risk management.

Furthermore, from the results of this study, the researcher realized that there were limitations that the further research could later develop. The research's limitation is that change commitment assessed by risk management certificate holders for changes is high, but the commitment needs to be looked at again for the change motives that led to the emergence of the commitment. It is necessary to specify whether the commitment arises because of the motive that wants to, needs to, or feels obligated to make changes. This motif looks the same, but the output behavior is different. According to Herscovith and Meyer (2002), commitment with the motive of wanting to make a change is the highest form of commitment in implementing a change in the organization. In addition, it is also obtained from the results that the readiness in confidence is still not significant the difference between high and low in the group of risk management certificate holders. What factors affect the efficacy assessment of risk management certificate holders needs to be looked at more deeply. This study has not been seen in detail what empirical factors make risk management certificate holders assess their confidence in making changes. 


\section{CONCLUSION AND FURTHER RESEARCH}

The conclusion of this research is empirical; organizational readiness for changes, reflected by competency-based risk management certificate holders as members of the organization, tends to be high. The context of the change is implementing risk management so the process will get more mature to answer the challenges of VUCA. This high level of readiness indicates that the risk management certificate holder is more prepared to initiate change, persistent in implementing changes, and cooperative towards existing changes.

It is also empirically shown that change commitment has more impact on forming high readiness than change efficacy. The high level of change commitment impacts the firm determination of risk management certificate holders for changes. Meanwhile, change efficacy, which tends to be high but not significant in certificate holders, can indicate that the beliefs that arise are still influenced by the shadow of unprepared factors that may exist in the organization or other organizational members.

The suggestion for further research is to conduct more profound research to see the motives of the commitments owned and assessed by risk management certificate holders using the theory of Herscovith and Meyer. In addition, further research can also explore the factors that influence the efficacy of risk management certificate holders to identify more profoundly and empirically why these beliefs are not as firm as commitment readiness. Also, further research can explore it from the dimensions of forming individual readiness with the theory of Holt et. al.

\section{REFERENCES}

Alijoyo, A. (2020). VUCA-The Context of Contemporary Risk. Jakarta: IRMAPA (Indonesian Risk Management Professional Association).

Bandura, A. (1986). Social Foundations of Thought and Action: A Social Cognitive Theory. New Jersey: Prentice-Hall.

Christensen, LB, Johnson, RB, \& Turner, LA (2015). Research Methods, Design, and analysis (12nd ed.). New York: Pearson.

Goodwin, CJ (2010). Research in psychology: Methods and design (6th ed.). John Wiley \& Sons Inc.

Holt, DT, Helfrich, CD, et al. (2010). Are You Ready? How Health Professionals Can Comprehensively Conceptualise Readiness for Change. Journal of J Gene Intern Med, 25 (Suppl 1): 50-55.

Herscovitch, L., Meyer, JP. (2002). Commitment to organizational change: Extension of a three-component model. Journal of Applied Psychology, 87(3):474-487.

Interview 1, with the Chairperson of IRMAPA (Indonesia Risk Management Professional Association); Charles R. Vorst, MM, CCGO, CGOP, CERG, ERMCP, QCRO, QRGP; 24 June 2021.

Interview 2, with the Secretary-General of the GRC Association; Victor Riwu Kaho ERMCP., CCGO., QRGP., CGRCEO., CGRCOP; 28 June 2021.

Jia, J., \& Bradbury, ME (2020). Complying with best-practice risk management committee guidance and performance. Journal of Contemporary Accounting \& Economics, 16(3). [scopus index, H:23]

Kalinga, J., \& Patrick, W. (2018). Implementation of Risk Management and Corporate Sustainability in the Canadian Oil and Gas Industry. Implementation of Risk Management, 3.

Kaplan, R. and Saccuzzo, D., (2013). Psychological Testing: Principles, Applications \& Issues, 8th ed. California: Cengage.

Lee Kaivo, J., \& Lauraeus, IT (2017). The VUCA Approach as a solution concept to Corporate Foresight Challenges and Global Technological Disruption. Foresight, 2.

Pedoman BNSP Indonesia No.301 tahun 2014 tentang Pelaksanaan Sertifikasi Kompetensi Kerja (PSKK) Reguler.

Permatasari, I. (2020). Does corporate governance affect bank risk management? Case study of Indonesian banks. International Trade, Politics, and Development, 27-139.

Sarkar, A. (2016). We live in a VUCA World: the importance of responsible leadership. Organizational Development and Learning: An International Journal, 30. 9-12. 10.1108/DLO-07-2015-0062.

Shea, CM, Jacobs, SR, Esserman, DA, Bruce, K., \& Weiner, BJ (2014). Organizational Readiness for Implementing Change: A Psychometric Assessment of a New Measure. Implementation Science, 9:7.

Susilo, LJ, \& Kaho, VR (2018). Risk Management: A Guide For Risk Leaders and Risk Practitioners. Jakarta: Grasindo.

VanVoorhis, CR, \& Morgan, BL (2007). Understanding Power and Rules of Thumb for Determining Sample Sizes. Tutorials in Quantitative Methods for Psychology, 43-50.

Weiner, BJ (2009). A Theory of Organization Readiness for Change. Implementation Science, 4:67. 